Correction

\title{
Correction: Warzecha, Z. et al. Protective Effect of Pretreatment with Acenocoumarol in Cerulein-Induced Acute Pancreatitis. Int. J. Mol. Sci. 2016, 17, 1709
}

\author{
Zygmunt Warzecha ${ }^{1, *}$, Paweł Sendur ${ }^{1,2}$, Piotr Ceranowicz ${ }^{1}$, Marcin Dembiński ${ }^{3}$, \\ Jakub Cieszkowski ${ }^{1}$, Beata Kuśnierz-Cabala ${ }^{4}$, Rafał Olszanecki ${ }^{5}$, Romana Tomaszewska ${ }^{6}$, \\ Tadeusz Ambroży ${ }^{7}$ and Artur Dembiński ${ }^{1}$ \\ 1 Department of Physiology, Faculty of Medicine, Jagiellonian University Medical College, \\ 16 Grzegórzecka St., 31-531 Cracow, Poland; p.send@interia.pl (P.S.); mpcerano@cyf-kr.edu.pl (P.C.); \\ jakub.cieszkowski@uj.edu.pl (J.C.); mpdembin@cyf-kr.edu.pl (A.D.) \\ 2 Department of Anesthesiology and Intensive Therapy, Faculty of Medicine, Jagiellonian University Medical \\ College, 31-501 Cracow, Poland \\ 3 The Second Department of General Surgery, Faculty of Medicine, Jagiellonian University Medical College, \\ 31-501 Cracow, Poland; mpmdembi@cyf-kr.edu.pl \\ 4 Department of Clinical Biochemistry, Faculty of Medicine, Jagiellonian University Medical College, \\ 31-501 Cracow, Poland; mbkusnie@cyf-kr.edu.pl \\ 5 Department of Pharmacology, Faculty of Medicine, Jagiellonian University Medical College, 31-531 Cracow, \\ Poland; rafal.olszanecki@uj.edu.pl \\ 6 Department of Pathology, Faculty of Medicine, Jagiellonian University Medical College, 31-531 Cracow, \\ Poland; romatom@mp.pl \\ 7 Faculty of Physical Education and Sport, University of Physical Education, 31-571 Cracow, Poland; \\ tadek@ambrozy.pl \\ * $\quad$ Correspondence: mpwarzec@cyf-kr.edu.pl; Tel.: +48-12-421-10-06; Fax: +48-12-422-54-78
}

Received: 11 June 2019; Accepted: 12 June 2019; Published: 13 June 2019

We would like to submit the correction to our published paper [1]. The reason for the correction is an error in the histological image presented in the published article. Two histological images (Figure 3A,B in [1]) are incorrect and, therefore, they need to be replaced with the correct new figure (Figure 1). 


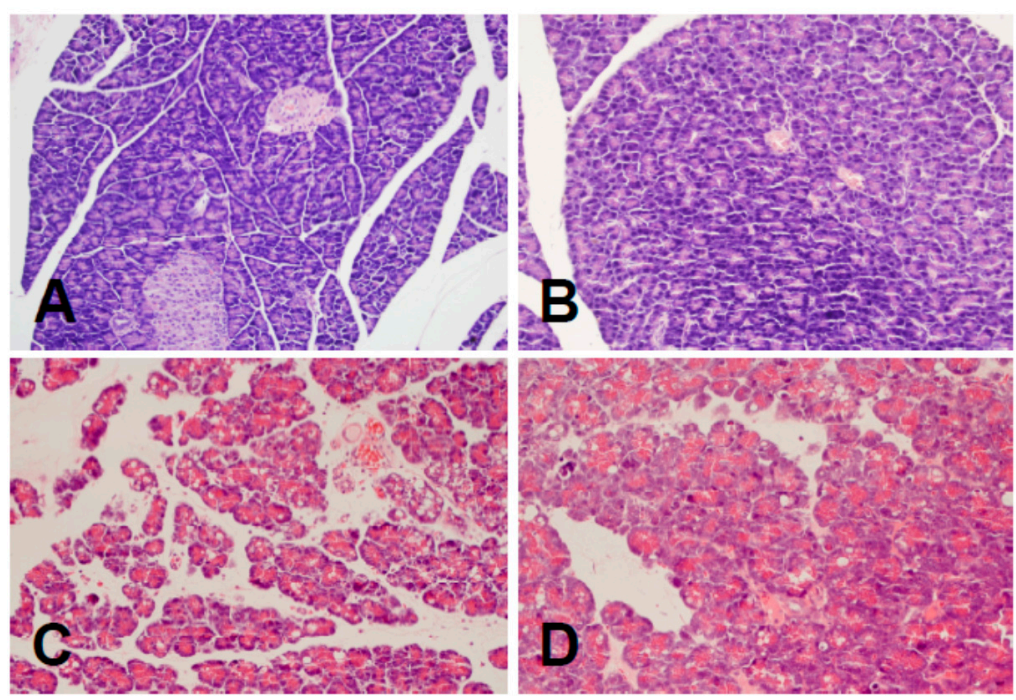

Figure 1. Representative morphological images of the pancreas observed in control rats treated with saline (A); rats pretreated with acenocoumarol at the dose of $50 \mu \mathrm{g} / \mathrm{kg} / \mathrm{day}$ without induction of acute pancreatitis (B); rats with cerulein-induced acute pancreatitis (C); rats pretreated with acenocoumarol (given the dose of $50 \mu \mathrm{g} / \mathrm{kg} /$ day) before induction of acute pancreatitis by cerulein (D). Hematoxylin-eosin counterstain, original magnification $200 x$.

The reported error does not have any material impact on the final results and conclusions of our published paper. We apologize for this inconvenient situation.

Conflicts of Interest: The authors declare no conflict of interest.

\section{Reference}

1. Warzecha, Z.; Sendur, P.; Ceranowicz, P.; Dembiński, M.; Cieszkowski, J.; Kuśnierz-Cabala, B.; Olszanecki, R.; Tomaszewska, R.; Ambroży, T.; Dembiński, A. Protective Effect of Pretreatment with Acenocoumarol in Cerulein-Induced Acute Pancreatitis. Int. J. Mol. Sci. 2016, 17, 1709. [CrossRef] [PubMed]

(C) 2019 by the authors. Licensee MDPI, Basel, Switzerland. This article is an open access article distributed under the terms and conditions of the Creative Commons Attribution (CC BY) license (http://creativecommons.org/licenses/by/4.0/). 